\title{
Gain Enhancement of a Microstrip Patch Antenna Using a Reflecting Layer
}

\author{
Anwer Sabah Mekki, ${ }^{1}$ Mohd Nizar Hamidon, ${ }^{1,2}$ Alyani Ismail, ${ }^{3}$ and Adam R. H. Alhawari ${ }^{3}$ \\ ${ }^{1}$ Functional Devices Laboratory, Institute of Advanced Technology, Universiti Putra Malaysia (UPM), \\ 43400 Serdang, Selangor, Malaysia \\ ${ }^{2}$ Department of Electrical and Electronic Engineering, Universiti Putra Malaysia (UPM), 43400 Serdang, Selangor, Malaysia \\ ${ }^{3}$ Wireless and Photonic Network Research Center, Department of Computer and Communication Systems Engineering, \\ Universiti Putra Malaysia (UPM), 43400 Serdang, Selangor, Malaysia \\ Correspondence should be addressed to Anwer Sabah Mekki; asmekki68@gmail.com
}

Received 20 December 2014; Revised 5 March 2015; Accepted 5 March 2015

Academic Editor: Giampiero Lovat

Copyright (C) 2015 Anwer Sabah Mekki et al. This is an open access article distributed under the Creative Commons Attribution License, which permits unrestricted use, distribution, and reproduction in any medium, provided the original work is properly cited.

\begin{abstract}
A low profile, unidirectional, dual layer, and narrow bandwidth microstrip patch antenna is designed to resonate at $2.45 \mathrm{GHz}$. The proposed antenna is suitable for specific applications, such as security and military systems, which require a narrow bandwidth and a small antenna size. This work is mainly focused on increasing the gain as well as reducing the size of the unidirectional patch antenna. The proposed antenna is simulated and measured. According to the simulated and measured results, it is shown that the unidirectional antenna has a higher gain and a higher front to back ratio $(\mathrm{F} / \mathrm{B})$ than the bidirectional one. This is achieved by using a second flame retardant layer (FR-4), coated with an annealed copper of $0.035 \mathrm{~mm}$ at both sides, with an air gap of $0.04 \lambda_{0}$ as a reflector. A gain of $5.2 \mathrm{~dB}$ with directivity of $7.6 \mathrm{dBi}, \mathrm{F} / \mathrm{B}$ of $9.5 \mathrm{~dB}$, and $-18 \mathrm{~dB}$ return losses $\left(S_{11}\right)$ are achieved through the use of a dual substrate layer of FR- 4 with a relative permittivity of 4.3 and a thickness of $1.6 \mathrm{~mm}$. The proposed dual layer microstrip patch antenna has an impedance bandwidth of $2 \%$ and the designed antenna shows very low complexity during fabrication.
\end{abstract}

\section{Introduction}

Microstrip patch antennas have been of interest for a long time due to their low profile, low cost, easy printability, and fabrication, as well as the capability of being embedded within other devices. However, there are many disadvantages, such as low gain and narrow bandwidth $[1,2]$. The gain of an antenna refers to the ratio of its radiation power in a specific direction to its power in the isotropic direction [3]. Many researchers are working to enhance the gain of the patch antennas using different designs, ideas, and materials [4-11]. On the other hand, narrow bandwidth system implementation improves system selectivity in a number of applications, including military, security, digital enhanced cordless telecommunications, and low power systems [12]. At the same time, due to the new technologies, most designers tend to reduce the size and increase the efficiency of the devices.
One of the common methods to enhance the gain and directivity is the use of reflector planes. In [13], using the concept of complementary antennas, a planer antenna is presented with a U-shaped metal reflector to achieve a unidirectional propagation; the resultant antenna has a low profile, high $\mathrm{F} / \mathrm{B}$, and high gain along the operating frequency range. Moreover, in [14], a multiple metal back reflector is proposed for a wideband slot antenna. In [15], using a metallic cavity shaped as a reflector with a magnetoelectric dipole antenna, the proposed antenna exhibits a high gain with high $\mathrm{F} / \mathrm{B}$ in the operating frequency range with relatively large dimensions.

But in [16], using a substrate rather than metal as a reflector is introduced to enhance the $\mathrm{F} / \mathrm{B}$ radiation with aperture coupled antennas. In [17], a high impedance surface (HIS), in the shape of arrays of square cells, is used to reduce the back lobe propagation. The design shows an enhancement in the gain along the frequency range and high F/B. In [18], 


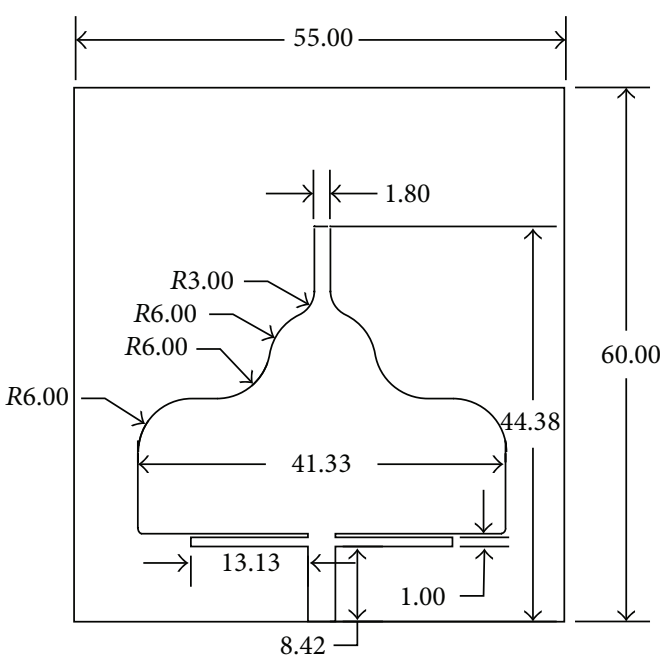

(a)

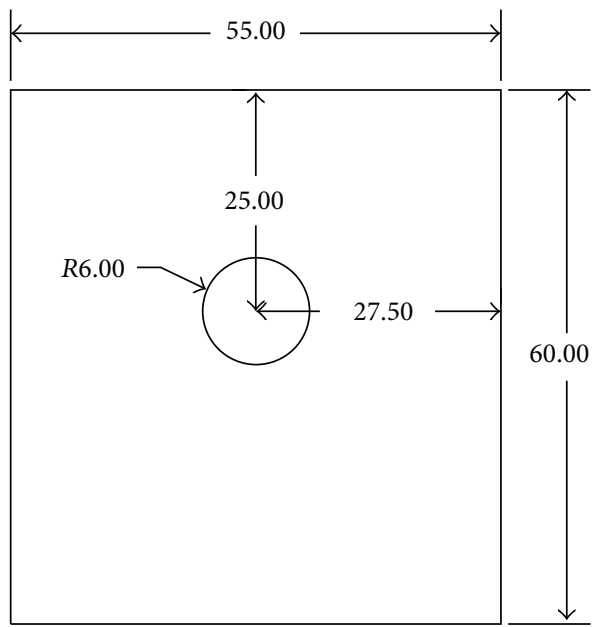

(b)

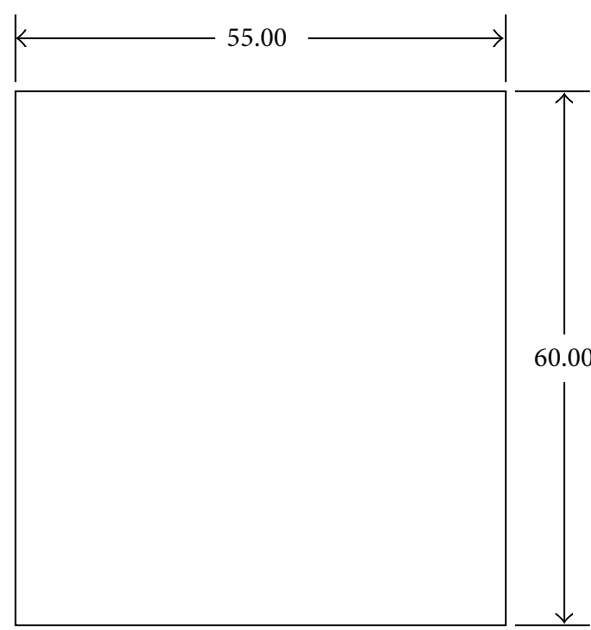

(c)

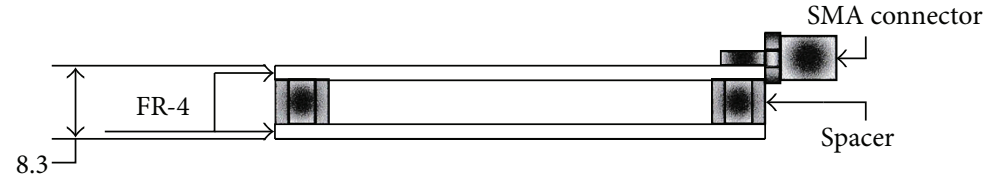

(d)

Figure 1: Proposed antenna design. (a) Patch antenna geometry, (b) ground side with circular slot, (c) second FR-4 layer (both sides), and (d) side view of the proposed antenna.

a dual band, unidirectional coplanar waveguide fed antenna (DB-CPWFA) is proposed. The reflector contains the ground plane, dielectric material, and artificial magnetic conductor. However, the dimensions of the antennas in the previous works are considered relatively large [13-18]. Therefore, achieving high gain while minimizing the size of the antenna is crucial.

In this paper, a new microstrip patch antenna is designed, simulated, and fabricated. The effect of the reflector layer on the gain and directivity is studied and evaluated. Furthermore, the air gap thickness between the two layers of the substrates is investigated. By tuning and optimization, the desired characteristics are achieved and the effect of the multigeometrical shapes is shown. The simulation results are compared to the DB-CPWFA [18] and the conventional microstrip patch antenna [19]. The simulated results are validated by the measurements and the effect of the reflector layer is verified. The measurement results demonstrate that the gain, directivity, and F/B ratio of the antenna have been significantly improved.

\section{Proposed Antenna}

The proposed dual-layer microstrip patch antenna design was developed by taking the design of the conventional square patch antenna, then changing it by removing symmetrical parts from the left and right sides, changing the right angles to curves, and finally introducing a circular slot in the ground plane. Finally, the proposed design is accomplished using a second layer of FR-4, which is coated with a copper film at both sides, spaced $0.04 \lambda_{0}$ from the ground layer.

In order to make the patch antenna operate at the desired characteristics, a tuning and optimization technique is introduced. Therefore, in order to make the design more flexible and workable during this procedure the proposed antenna contains multigeometrical details. In antenna designs, sacrificing some parameters is compulsory in order to enhance others [20].

Figure 1 illustrates the dimensions of the proposed antenna. The overall dimensions are $60 \mathrm{~mm} \times 55 \mathrm{~mm} \times 8.3 \mathrm{~mm}$. The substrate is FR-4, with a permittivity of 4.3 and loss 


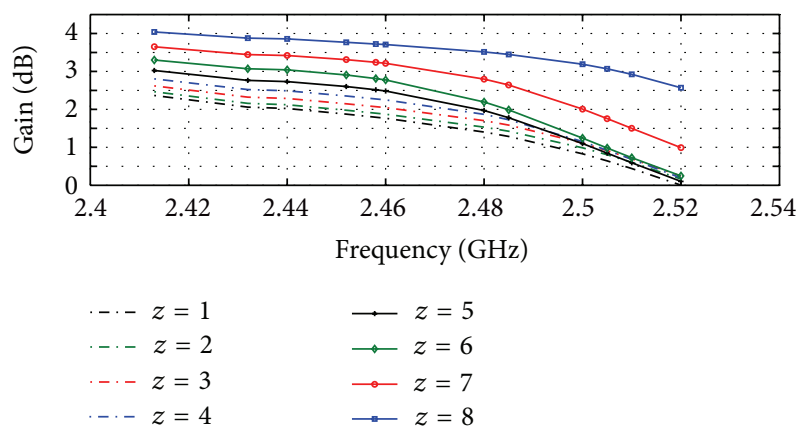

Figure 2: Effect of ground circular slot on the gain.

tangent of 0.025 , coated with annealed copper of $0.035 \mathrm{~mm}$ thickness at both sides. Four spacers are used, which are made of Teflon PTFE (polytetrafluoroethylene), which is a lossy material, with 2.1 relative permittivity. A second FR-4 layer, which is coated with annealed copper of $0.035 \mathrm{~mm}$ thickness at both sides, is placed at a distance of $0.04 \lambda_{0}$ from the first FR-4 layer. The second FR-4 layer acts as a reflector to redirect the propagation density from the back lobe to the main lobe. Hence, for the same radiation efficiency, increasing the directivity, $D$, means increasing the gain, $G$, as follows [3]:

$$
G=\eta D
$$

where $\eta$ is the radiation efficiency.

The patch antenna is fed using a microstrip feed transmission line with $50 \Omega$ characteristic impedance, $8.2 \mathrm{~mm}$ length, and $3 \mathrm{~mm}$ width. The inset feed transmission line is connected to the port using a subminiature version A (SMA) connecter.

\section{Simulation Results}

The proposed design was simulated using CST-MW studio; the design was done through three main stages. The first stage consisted of a primary design, which contained a single layer antenna with a full ground plane. The characteristics of the first stage antenna were enhanced in the second stage by introducing a circular slot of $6 \mathrm{~mm}$ radius in the ground layer. The slot radius was chosen through sweeping the radius in the simulation from zero to $8 \mathrm{~mm}$. Figure 2 shows the effect of the radius $(z)$ in $\mathrm{mm}$ of the circular slot on the gain of the second stage. From Figure 2, it can be shown that the gain can be increased by increasing the radius of the slot. However, this will increase the return losses; therefore, it is a matter of tradeoff between the gain and return losses. At the last stage, a second substrate layer, which is coated with $0.035 \mathrm{~mm}$ copper films at both sides, is added at a distance of $0.04 \lambda_{0}$ from the ground layer and fixed using four cylindrical PTFE spacers with outer diameter of $6.5 \mathrm{~mm}$ and inner diameter of $3 \mathrm{~mm}$ as shown in Figure 3.

The characteristics of the three stages, the DB-CPWFA [18], and the conventional square patch antenna [19] are illustrated in Table 1. It can be observed that, from Table 1, the proposed antenna outperforms both the conventional

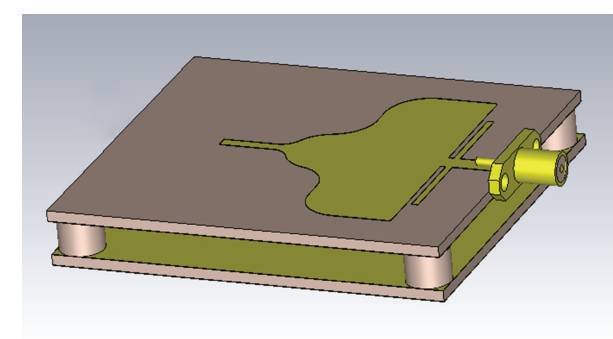

FIGURE 3: Perspective view of the proposed antenna.

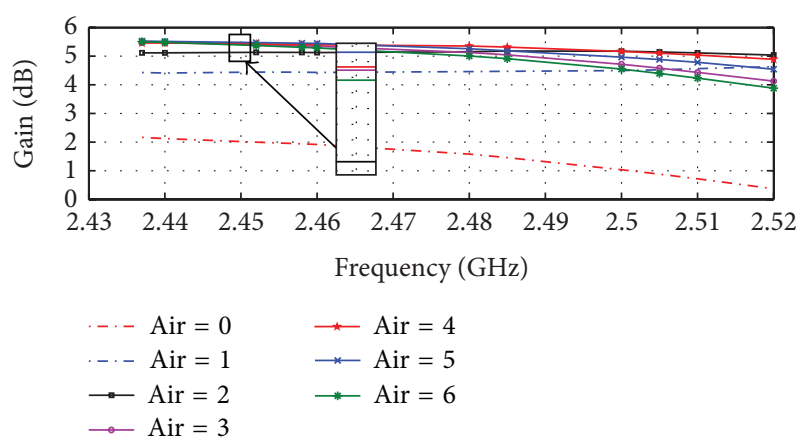

FIGURE 4: Effect of air gap thickness on the gain at desired frequency.

one in terms of matching impedance and gain and the DBCPWFA in terms of matching impedance, complexity, and a significant size reduction of $67.4 \%$ with a comparable gain. Since the gain is directly proportional to the effective area of the antenna [3], the resultant simulated gain of the proposed antenna is considered comparable to that of the DB-CPWFA.

The effect of the air gap distance on the gain of the dual layer microstrip patch antenna at the desired frequency is shown in Figure 4. The values of air, in Figure 4, represent the distance in $\mathrm{mm}$ between the two-substrate layers. In comparison with the conventional microstrip patch antenna, it is clear that there is an increment in the gain along the distance range from air $=1 \mathrm{~mm}$ to air $=6 \mathrm{~mm}$. The curve reaches the maximum value at the desired frequency with an air gap distance of $5 \mathrm{~mm}$.

The directivity of the three stages and the conventional microstrip patch antenna are listed in Table 2.

Figures 5-8 show the far field directivity of the three stages and the conventional square patch antenna. The red color indicates the far field region, the angle of the main lobe direction is colored with blue, and the green color indicates the maximum value of the back lobe direction. With the spacing value chosen of $0.04 \lambda_{0}$, the reflected radiation from the second layer reinforces the main lobe radiation. As a result, the main lobe is increased. Accordingly, the gain is increased by $2.16 \mathrm{~dB}$ as compared to the conventional microstrip patch antenna. Moreover, an approximately perfect matching is achieved; the impedance of the proposed antenna is $(49.3+$ j3.88) $\Omega$ with a quality factor of 16.8 and $F / B$ ratio of $9.5 \mathrm{~dB}$. 
TABLE 1: Comparison of the antennas' parameters.

\begin{tabular}{|c|c|c|c|c|c|c|c|c|c|}
\hline \multirow{2}{*}{ Design } & \multirow{2}{*}{$f_{r}(\mathrm{GHz})$} & \multirow{2}{*}{$S_{11}(\mathrm{~dB})$} & \multicolumn{2}{|c|}{$G(\mathrm{~dB})$} & \multirow{2}{*}{$D(\mathrm{dBi})$} & \multirow{2}{*}{$\eta$} & \multirow{2}{*}{ VSWR } & \multirow{2}{*}{$\begin{array}{c}\text { Impedance BW } \\
(\mathrm{MHz})\end{array}$} & \multirow{2}{*}{$\begin{array}{c}\text { Size }\left(L_{s} \times W_{s} \times H\right) \\
\mathrm{mm}^{3}\end{array}$} \\
\hline & & & Sim. & Mrd. & & & & & \\
\hline First stage & 2.423 & -7.85 & 2.22 & & 6.340 & 0.386 & 2.326 & - & $55 \times 60 \times 1.6$ \\
\hline Second stage & 2.411 & -25.028 & 3.30 & & 5.938 & 0.544 & 1.118 & 42.8 & $55 \times 60 \times 1.6$ \\
\hline $\begin{array}{l}\text { Third stage (proposed } \\
\text { design) }\end{array}$ & 2.45 & -28.028 & 5.4 & 5.2 & 7.747 & 0.582 & 1.082 & 44.7 & $55 \times 60 \times 8.37$ \\
\hline DB-CPWFA [18] & $2.45 \& 5.8$ & $-15 \&-37$ & $7 \& 6.8$ & $6 \& 8.5$ & - & - & - & $245 \& 745$ & $100 \times 120 \times 7$ \\
\hline Conventional [19] & 2.344 & -12.617 & 3.11 & & 5.02 & 0.64 & 1.61 & 64.8 & $40 \times 40 \times 1.6$ \\
\hline
\end{tabular}

$f_{r}$ is the resonance frequency, Sim. is the simulated gain, Mrd. is the measured gain, VSWR is the voltage standing wave ratio, $W_{s}$ is the width of the substrate, $L_{s}$ is the length of the substrate, and $H$ is the height of the antenna.

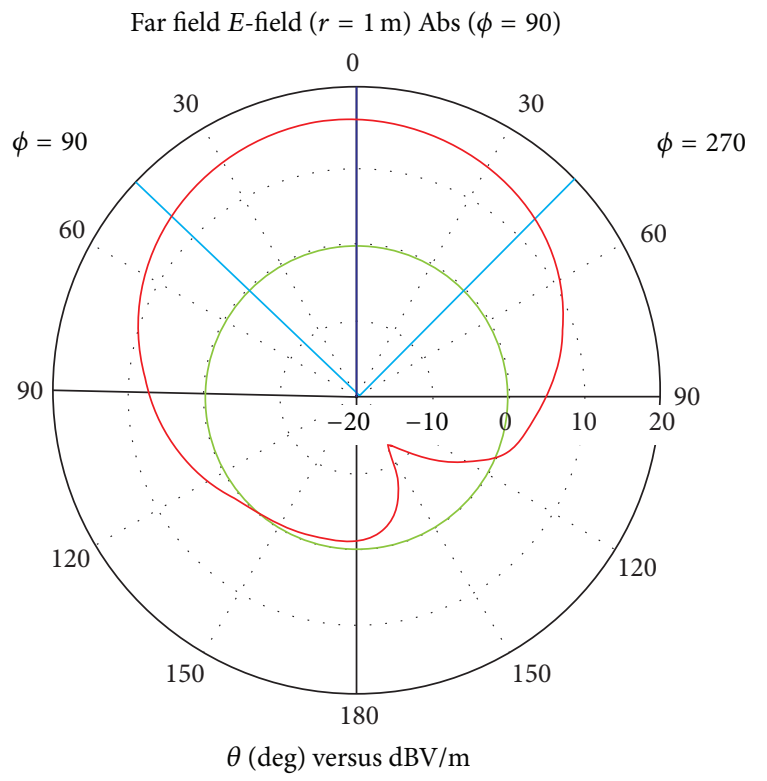

(a)

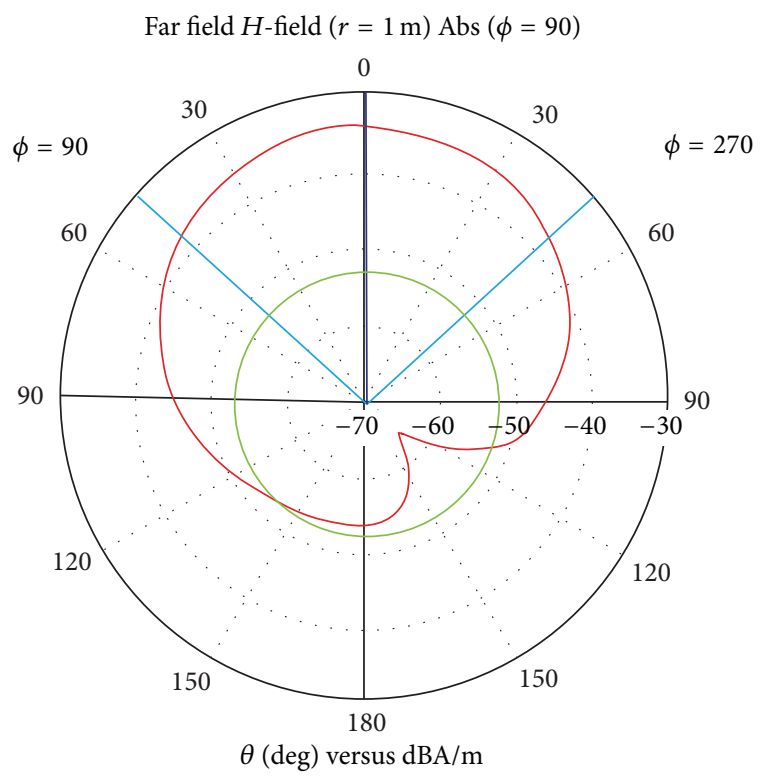

(b)

FIGURE 5: First stage of proposed antenna. (a) E-field and (b) $H$-field.

\section{Fabrication and Measurements}

Using FR-4 substrates with $\varepsilon_{r}$ of 4.3 , the proposed antenna has been fabricated. The second layer is fixed at $5 \mathrm{~mm}$ using four Teflon spacers and thin films of solvent adhesive with $\varepsilon_{r}$ of 2. The dual layer microstrip patch antenna is connected to $50 \Omega$ SMA connector. The overall dimensions are $60 \mathrm{~mm} \times$ $55 \mathrm{~mm} \times 8.3 \mathrm{~mm}$; the $8.3 \mathrm{~mm}$ equals $0.069 \lambda_{0}$. The $S_{11}$ parameter of the fabricated antenna is measured using a vector network analyzer (Anritsu 37347D). The gain of the fabricated antenna is measured using a vector signal generator (Anritsu MG3700A), a spectrum analyser (Advantest R3267), and a two-horn antenna with dual polarization (A-INFOMW). Figure 9 shows the fabricated dual layer of the proposed microstrip patch antenna.

The differences in values between the simulation and measurement results are due to the effect of analogue losses and deficiencies. These factors cannot be taken in to account using the currently available simulation software.
In Figure 10, a comparison of $S_{11}$ parameter between simulated and measured results is shown. The measured value of $S_{11}$ is $-18 \mathrm{~dB}$ while the simulated value is $-28 \mathrm{~dB}$. The measured gain of the proposed antenna is $5.2 \mathrm{~dB}$ and it is comparable with the simulated gain, which is $5.4 \mathrm{~dB}$. In comparison with the DB-CPWFA, the measured gain of the proposed antenna is close to the measured gain of the DBCPWFA, which is $6 \mathrm{~dB}$, as shown in Table 1 .

\section{Conclusion}

A unidirectional and low profile microstrip patch antenna of $0.069 \lambda_{0}$ has been introduced. Using a second layer of FR-4, which is coated with copper, reduced the back lobe and enhanced the gain up to $5.4 \mathrm{~dB}$ as well as increased the directivity up to $7.74 \mathrm{dBi}$ with $\mathrm{F} / \mathrm{B}$ ratio of $9.5 \mathrm{~dB}$. Moreover, the proposed antenna shows flexibility during the optimization technique and the simulation results are evaluated by measurements. 
TABLE 2: Comparison of the directivity of the proposed antenna (three stages) and the conventional microstrip patch antenna [19].

\begin{tabular}{lccccc}
\hline Design & $f_{r}(\mathrm{GHz})$ & $\begin{array}{c}\text { Main lobe } \\
\text { magnitude } \\
(E \text {-field) dBV/m }\end{array}$ & $\begin{array}{c}\text { Main lobe } \\
\text { magnitude } \\
(H \text {-field) dBA/m }\end{array}$ & $\begin{array}{c}\text { Main lobe } \\
\text { direction } \\
\text { (degree) }\end{array}$ & $\begin{array}{c}\text { Angular width } \\
\text { at 3 dB (degree) }\end{array}$ \\
\hline $\begin{array}{l}\text { First stage } \\
\text { Second stage }\end{array}$ & 2.365 & -35.3 & 16.2 & 0.0 & 92.2 \\
$\begin{array}{l}\text { Third stage (proposed } \\
\text { antenna) }\end{array}$ & 2.353 & -33.5 & 18.1 & 6 & 84.4 \\
\begin{tabular}{l} 
Conventional [19] \\
\hline
\end{tabular} & 2.392 & -31.4 & 20.2 & 6 & 7.6 \\
\hline
\end{tabular}

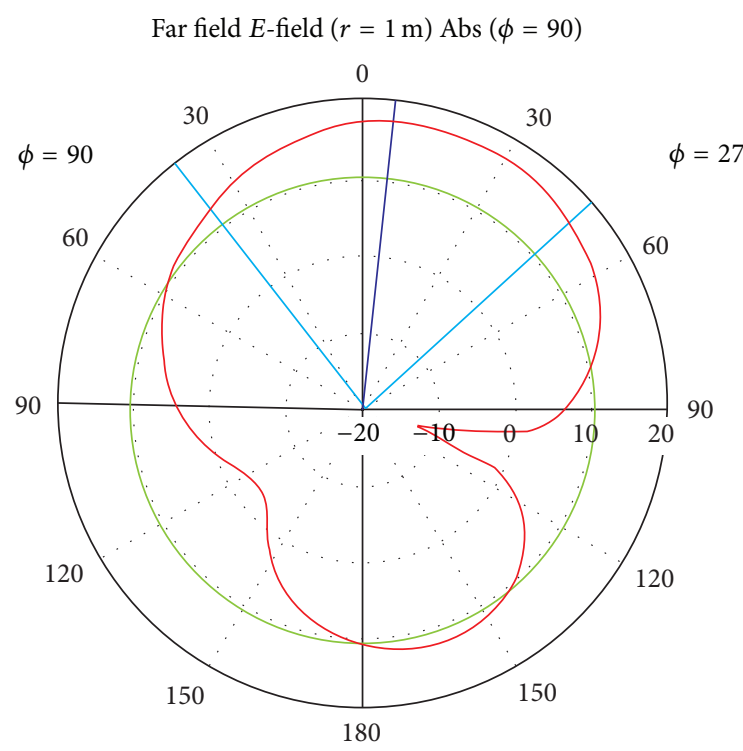

$\theta(\mathrm{deg})$ versus $\mathrm{dBV} / \mathrm{m}$

(a)

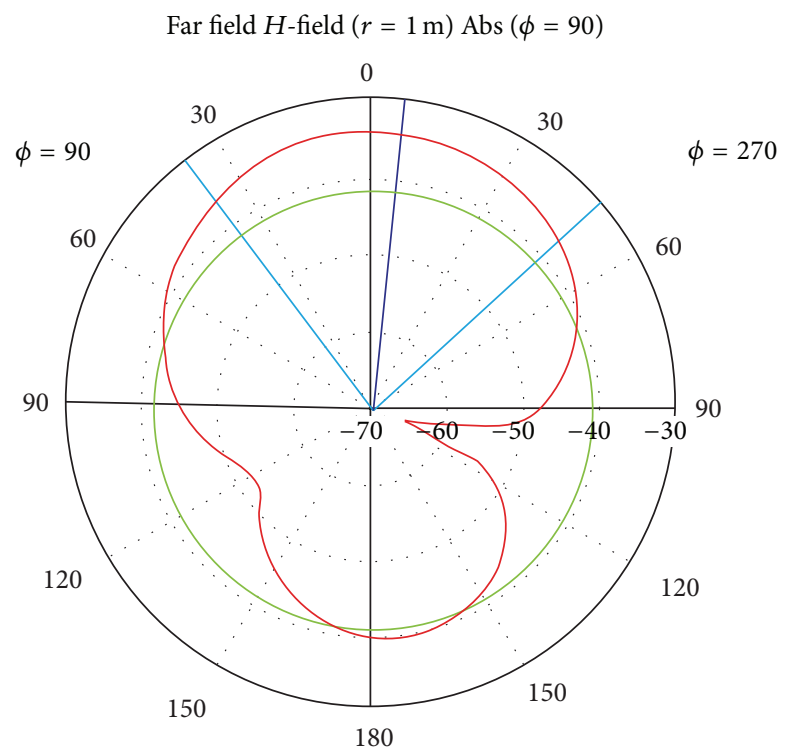

$\theta(\mathrm{deg})$ versus $\mathrm{dBA} / \mathrm{m}$

(b)

FIGURE 6: Second stage of proposed antenna. (a) E-field and (b) $H$-field.

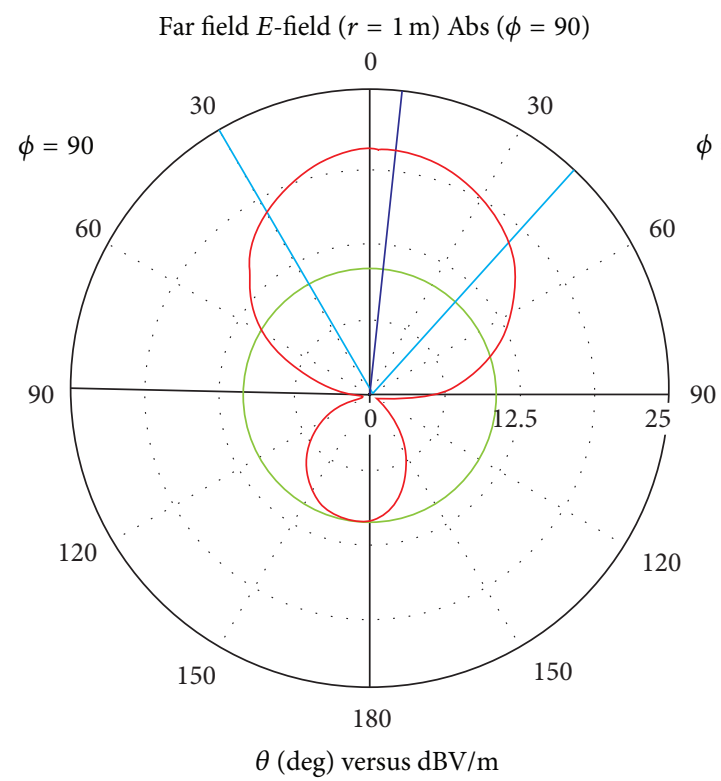

(a)

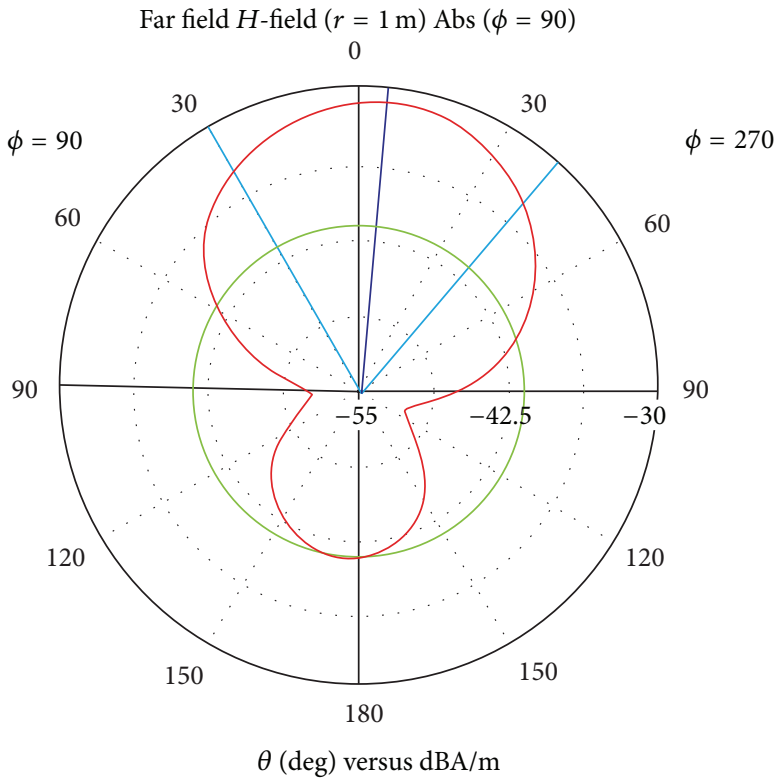

(b)

FIGURE 7: Third stage (final) of proposed antenna. (a) E-field and (b) $H$-field. 


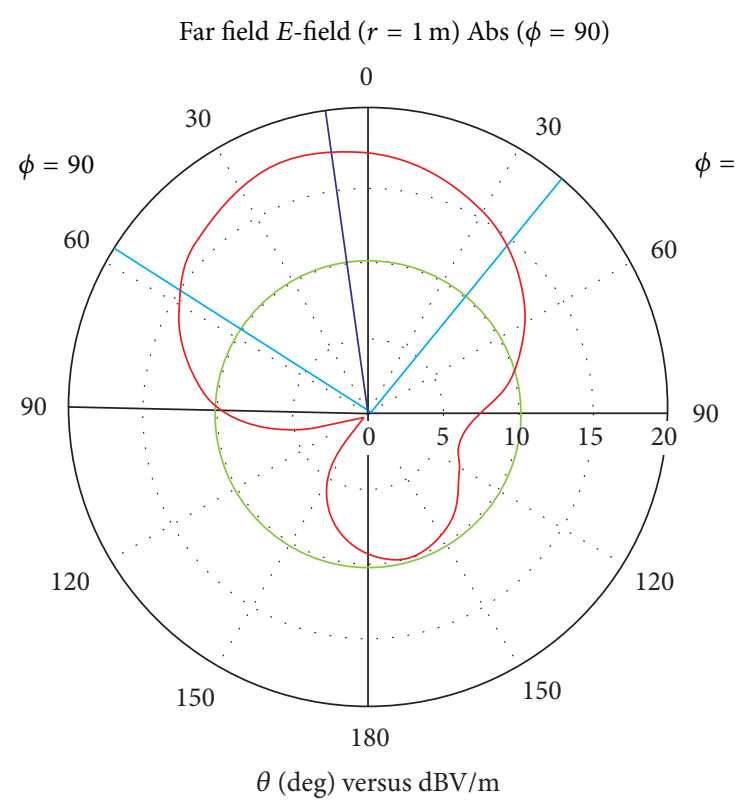

(a)
Far field $H$-field $(r=1 \mathrm{~m})$ Abs $(\phi=90)$

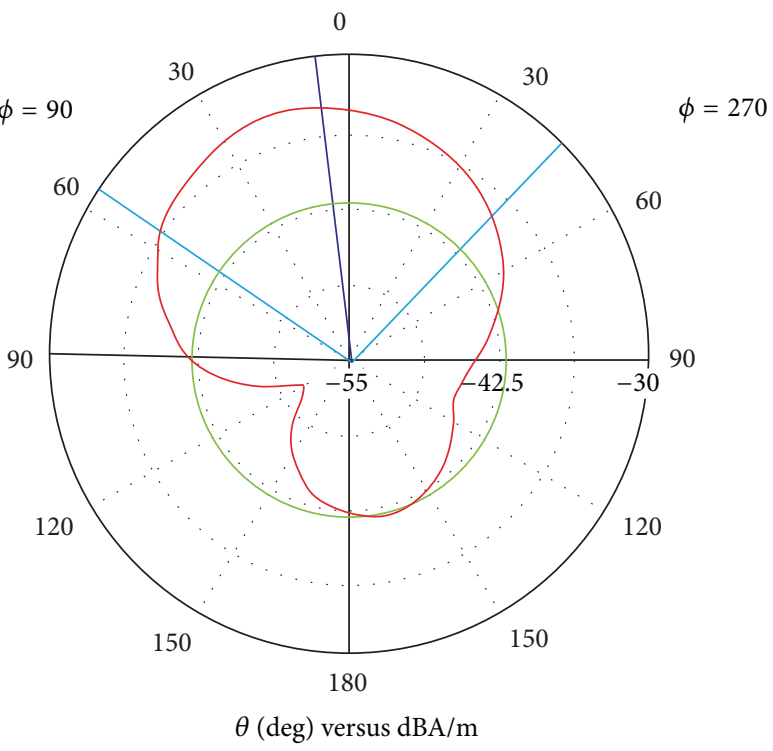

(b)

Figure 8: Conventional microstrip patch antenna. (a) $E$-field and (b) $H$-field.

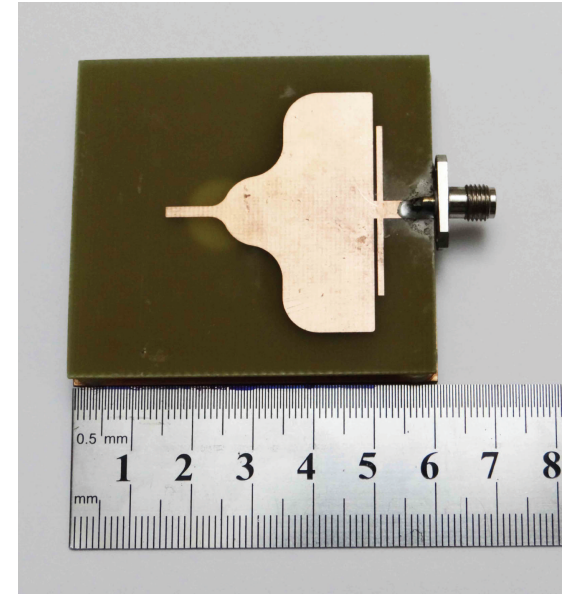

FIGURE 9: Fabricated antenna.

The proposed antenna is compatible for specific applications, such as security and military systems, due to considerable gain, small size, low profile, and unidirectional propagation. Furthermore, it is easily fabricated at low cost and low complexity.

The proposed antenna outperforms both the conventional one in terms of the matching impedance and gain and the DB-CPWFA in terms of matching impedance and a significant size reduction of $67.4 \%$ with a comparable gain.

\section{Conflict of Interests}

The authors declare that there is no conflict of interests regarding the publication of this paper.

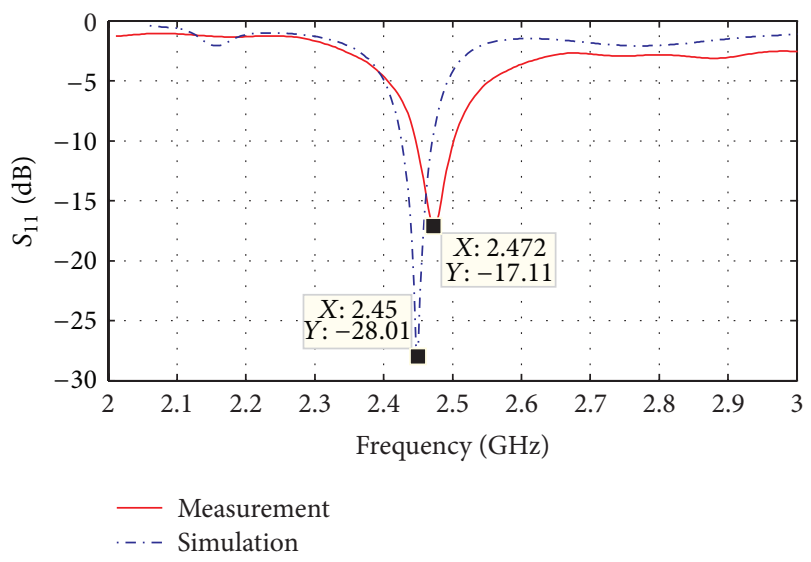

FIGURE 10: Simulated and measured return losses.

\section{References}

[1] C.-L. Mak, H. Wong, and K.-M. Luk, "High-gain and wide-band single-layer patch antenna for wireless communications," IEEE Transactions on Vehicular Technology, vol. 54, no. 1, pp. 33-40, 2005.

[2] J.-W. Kim, T.-H. Jung, H.-K. Ryu, J.-M. Woo, C.-S. Eun, and D.-K. Lee, "Compact multiband microstrip antenna using inverted-L- and T-shaped parasitic elements," IEEE Antennas and Wireless Propagation Letters, vol. 12, pp. 1299-1302, 2013.

[3] D. M. Pozar, Microwave Engineering, John Wiley \& Sons, New York, NY, USA, 4th edition, 2012.

[4] I. Zivkovic and K. Scheffler, "A new inovative antenna concept for both narrow band and UWB applications," Progress in Electromagnetics Research, vol. 139, pp. 121-131, 2013. 
[5] H. A. Majid, M. K. A. Rahim, and T. Masri, "Microstrip antenna's gain enhancement using left-handed metamaterial structure," Progress In Electromagnetics Research M, vol. 8, pp. 235-247, 2009.

[6] B. Yildirim and B. A. Cetiner, "Enhanced gain patch antenna with a rectangular loop shaped parasitic radiator," IEEE Antennas and Wireless Propagation Letters, vol. 7, pp. 229-232, 2008.

[7] S. B. Yeap and Z. N. Chen, "Microstrip patch antennas with enhanced gain by partial substrate removal," IEEE Transactions on Antennas and Propagation, vol. 58, no. 9, pp. 2811-2816, 2010.

[8] K. Mandal and P. P. Sarkar, "High gain wide-band U-shaped patch antennas with modified ground planes," IEEE Transactions on Antennas and Propagation, vol. 61, no. 4, pp. 2279-2282, 2013.

[9] Z. Park, C. Li, and J. Lin, "A broadband microstrip antenna with improved gain for noncontact vital sign radar detection," IEEE Antennas and Wireless Propagation Letters, vol. 8, pp. 939-942, 2009.

[10] Z. Liu, P. Wang, and Z. Zeng, "Enhancement of the gain for microstrip antennas using negative permeability metamaterial on low temperature co-fired ceramic (LTCC) substrate," IEEE Antennas and Wireless Propagation Letters, vol. 12, pp. 429-432, 2013.

[11] A. Rivera-Albino and C. A. Balanis, "Gain enhancement in microstrip patch antennas using hybrid substrates," IEEE Antennas and Wireless Propagation Letters, vol. 12, pp. 476-479, 2013.

[12] C. A. Balanis, Antenna Theory Analysis and Design, John Wiely \& Sons, 3rd edition, 2005.

[13] M. Li and K.-M. Luk, "A low-profile wideband planar antenna," IEEE Transactions on Antennas and Propagation, vol. 61, no. 9, pp. 4411-4418, 2013.

[14] X. Gao, Y. Qi, and Y.-C. Jiao, "Design of multiplate backreflector for a wideband slot antenna," IEEE Antennas and Wireless Propagation Letters, vol. 12, pp. 773-776, 2013.

[15] L. Ge and K. M. Luk, "A low-profile magneto-electric dipole antenna," IEEE Transactions on Antennas and Propagation, vol. 60, no. 4, pp. 1684-1689, 2012.

[16] Q. Rao, T. A. Denidni, and R. H. Johnston, "Dielectric reflector backed aperture-coupled antennas for reduced back radiation," IEEE Transactions on Electromagnetic Compatibility, vol. 48, no. 2, pp. 287-291, 2006.

[17] X. Mu, W. Jiang, S.-X. Gong, and F.-W. Wang, "Dual-band low profile directional antenna with high impedance surface reflector," Progress in Electromagnetics Research Letters, vol. 25, pp. 67-75, 2011.

[18] Q. Luo, H. Tian, Z. Huang, X. Wang, Z. Guo, and Y. Ji, "Unidirectional dual-band CPW-fed antenna loaded with an AMC reflector," International Journal of Antennas and Propagation, vol. 2013, Article ID 875281, 10 pages, 2013.

[19] C. Kamtongdee and N. Wongkasem, "A novel design of compact $2.4 \mathrm{GHz}$ microstrip antennas," in Proceedings of the 6th International Conference on Electrical Engineering/Electronics, Computer, Telecommunications and Information Technology, vol. 4, pp. 766-769, May 2009.

[20] W. L. Stutzman and G. A. Thiele, Antenna Theory and Design, John Wiley \& Sons, 3rd edition, 2013. 

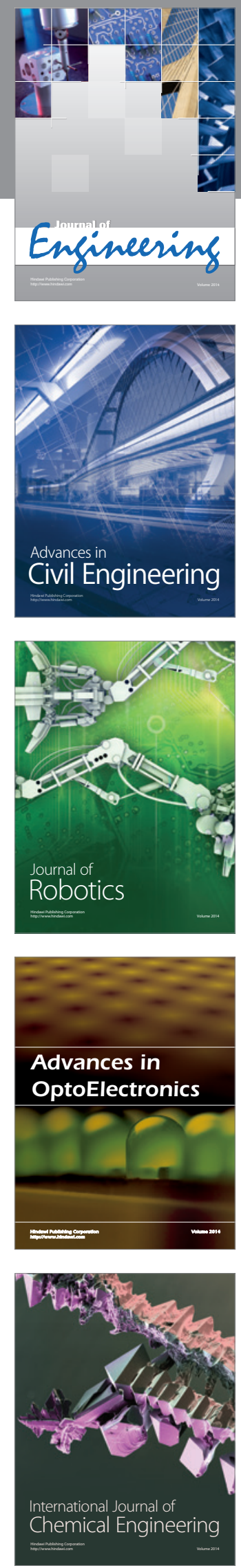

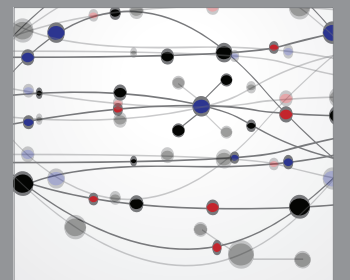

The Scientific World Journal
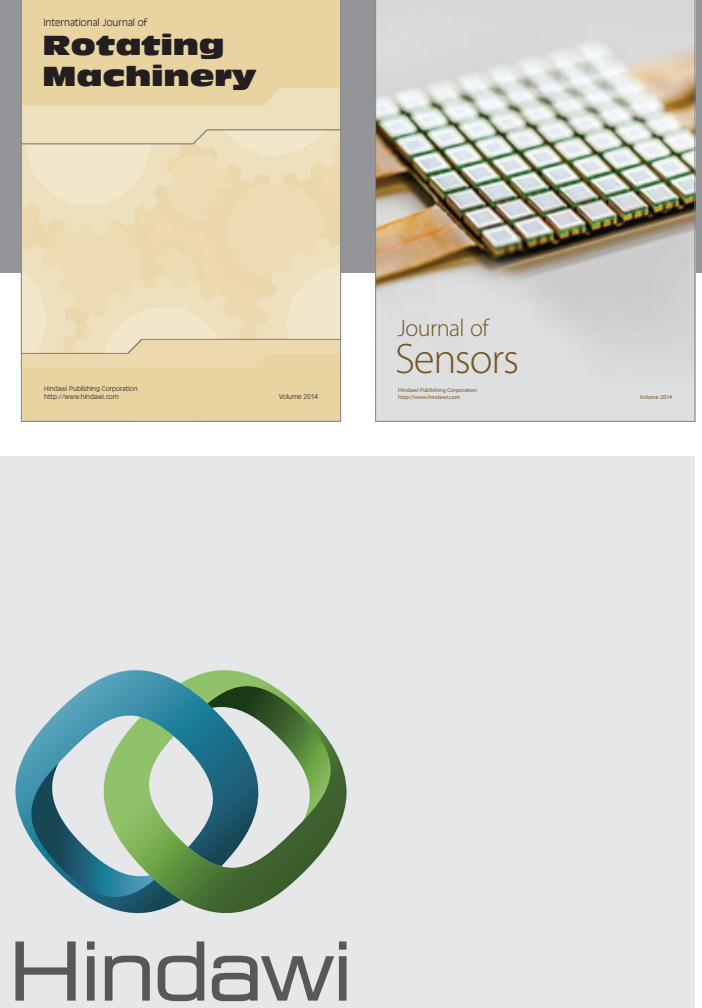

Submit your manuscripts at http://www.hindawi.com
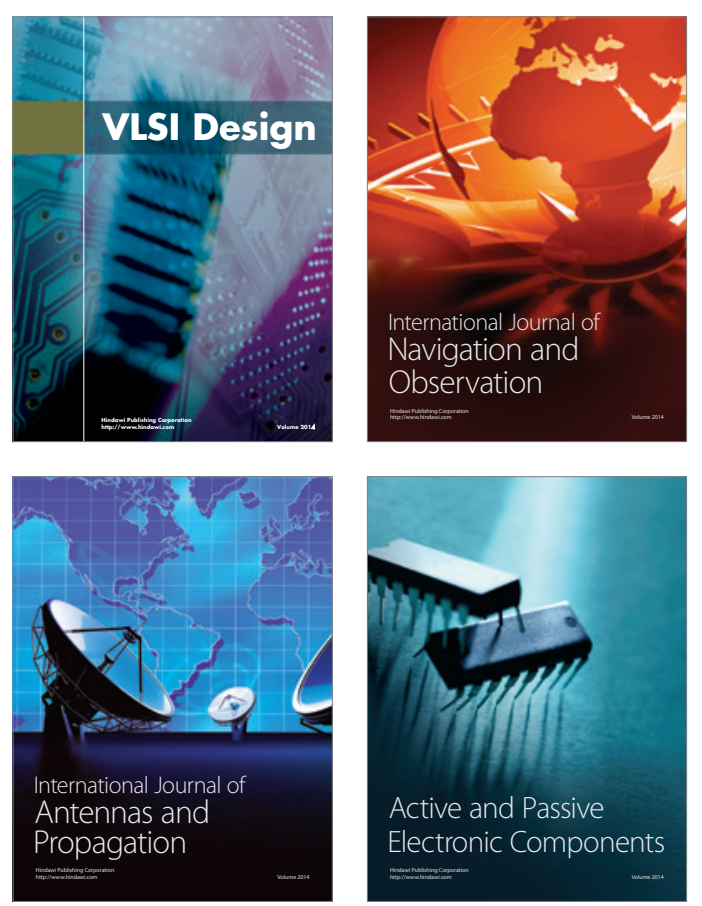
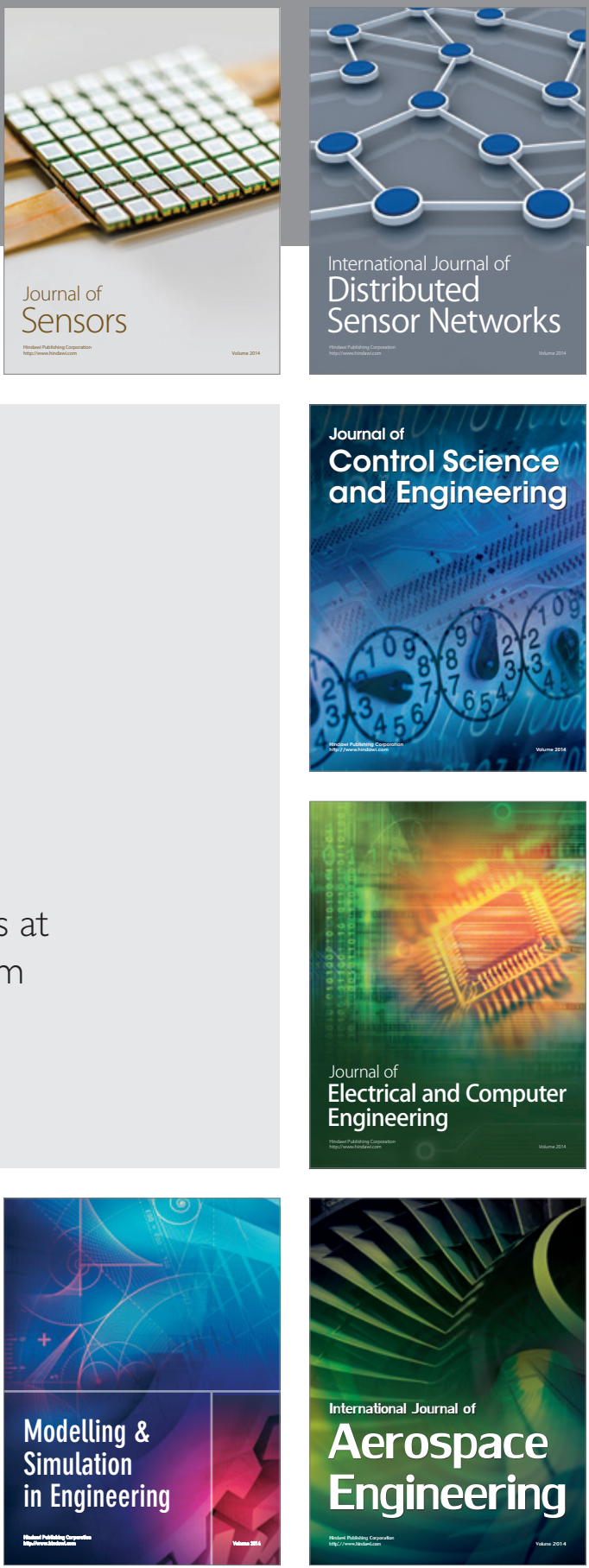

Journal of

Control Science

and Engineering
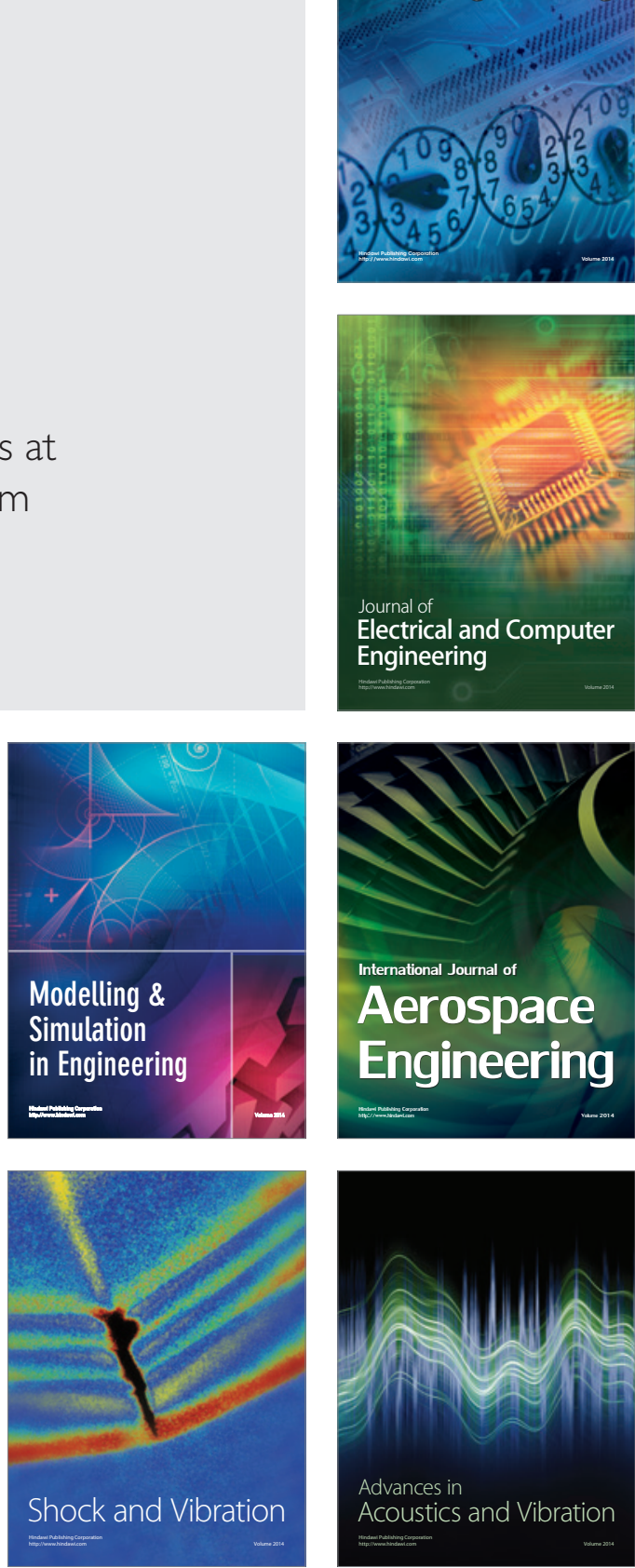